\title{
A CONTRIBUTION TO RESEARCH OF DEGRADATION OF CHARACTERISTICS OF VIBRATION PARAMETERS ON VIBRATION ASPECT OF VEHICLE COMFORT
}

\author{
Dr Miroslav Demić * \\ University of Kragujevac, Faculty of Engineering Science, Kragujevac, Serbia \\ Dr Đorđe Diligenski \\ Vinča Institute of Nuclear Sciences, Department of Motor Vehicles and IC engines, Belgrade, Serbia
}

Dynamic simulation, based on modeling, has a significant role in vehicle development, especially in the early stages of design process, when relevant parameters are being defined. In praxis it is usually assumed that vibration parameters are unchangeable, what is basically wrong. All researches indicate that vibration parameters degrade in time of vehicle service, consequently leading to a variation of its dynamic characteristics. This paper, based on preliminary research results, attempts to point out the necessity of taking into consideration this variation in the earliest phases of vehicle design by its implementation in the vehicle simulation model.

Key words: Vehicle, Vibration parameters, Degradation, Vibration comfort

\section{INTRODUCTION}

Dynamic simulation has important role in development of motor vehicles, based on modeling, by use of application of numerous vehicle models $[05-16,22,24-26,28,29]$. It can be assumed that the mechanical model, in the general form, is described by the equation $[05,06]$ :

$$
\dot{Z}=\dot{Z}(Z, A, U, L, Q, t)
$$

where:

- Z - vector of generalized coordinates of the vibration system,

- A - vector of vehicle vibration parameters,

- $U$ - vector of control functions,

- $Q$ - time function of excitation (coming from road microprofile, engine function, unbalanced masses, tire nonuniformities, etc.),

- $\mathrm{L}$ - function that takes into account stochastic variation of characteristics of vibration parameters during the vehicle service life, and

- $\mathrm{t}$ - time.

General solution of vector differential equation (1) can be written in the form [05-06]:
$Z=Z(A, U, L, t)$

The simplest case is when there does is no control function $(\mathrm{U}=0)$ and when variation of vibration parameters of a vehicle in service is not taken into account $(L=0)$, i.e.:

$Z=Z(A, t)$

In practice, a simplification given by expression (3) is commonly used, which neglects the influence of duration of service time on variation of vehicle vibration parameters. However, it represents a major simplification, according to [23], where the existence of the mentioned variation is shown. Therefore, this problem will be considered in details by application of the appropriate vehicle vibration model.

\section{SELECTION OF VEHICLE VIBRATION MODEL}

The structure of a vehicle model is chosen with regard to the variables supposed to be analyzed $[04,05]$. Therefore, vibration model of various structure and complexity [05-16,20-22,24-31]. The vehicle model should be chosen to be as simple as possible, and to enable simulation of the desired value $[05,06]$. A vehicle vibration model, often regarded in literature as quarter 
model $[21,22,24,26,28,29]$, given in Figure 1, has been estimated to be optimal for the observation, bearing in mind that the aim of this research was to introduce degradation of vibration parameters in the model.

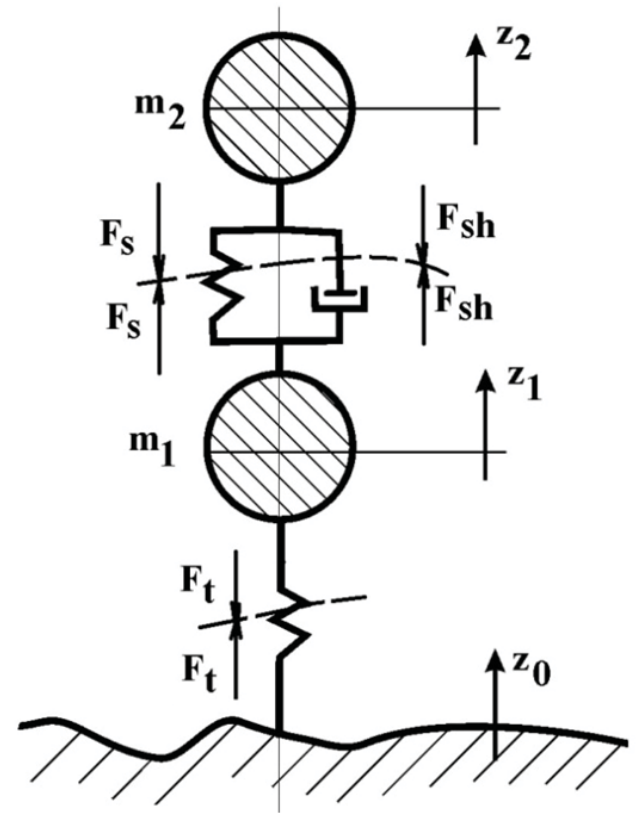

Figure 1: The equivalent vehicle model

Where the following signs were applied:

- $\mathrm{m}_{1}, \mathrm{~m}_{2}$-unsprung and sprung mass of quarter vehicle model, respectively (in this case 27.5 and $250 \mathrm{~kg}$ ),

- Fs - force in the spring,

- Fsh - force in the shock absorber, and

- $\mathrm{Ft}$ - force in the tire.

Force in the tire can be represented by the polynomial equation of the third degree [05-15, 20,21,23,25]:

$$
F_{o p}=c_{1} \Delta z+c_{2} \Delta z^{3}
$$

where:

- $\mathrm{c}_{1}$ and $\mathrm{c}_{2}$ - stiffness parameters, and

- $\Delta z$ - spring relative deformation.

Force in the shock absorber depends not only on the relative speed but on the relative motion and acceleration [01, 16]. The analyses have shown that the model defined in $[01,16]$, which applies transcendent functions of acceleration, can hardly be used in modeling of vehicles with more than one degree of freedom. That comes from the fact that the acceleration is covered by the function tangens hyperbolicus, in which case problems of decoupling of differential equations of motion, for model with two or more degrees of freedom of motion. Besides, it appears that the acceleration is of minor influence on the force than displacement and velocity, so for further analyses a model $[01,16]$ has been adopted, where the force is described with the expression:

$$
\begin{aligned}
& F_{s h}=\left\{x_{1}+x_{2,3} \cdot \Delta \dot{z}+x_{4} \cdot \Delta \dot{z}^{2} \operatorname{sigh}(\Delta \dot{z})\right\} . \\
& \left\{x_{5}+x_{6} \cdot \operatorname{th}\left(\frac{\Delta z}{3 \cdot \sigma_{\Delta z}}\right)\right\}
\end{aligned}
$$

where:

- $\Delta z$ and $\Delta \dot{z}$ - relative displacement and velocity, respectively, and

- $\mathrm{x}_{1}, \mathrm{x}_{2}{ }_{3}, \mathrm{x}_{4}, \mathrm{x}_{5}$ and $\mathrm{x}_{6}$ - parameters of shock absorber model.

Radial force in the tire is also nonlinear $[20,21,23,25]$, and therefore the following expression is used:

$$
F_{p}=c_{3} \Delta+c_{4} \Delta^{2}+c_{5} \Delta^{3}
$$

where:

- $\Delta$-radial deformation of the tire, and

- $\mathrm{C}_{3}, \mathrm{C}_{4}$ and $\mathrm{C}_{5}-$ parameters of tire radial stiffness.

As it is well known, vertical vehicle vibration depend on type of road, velocity and the number of passengers riding in the vehicle. Having that in mind, the analysis is performed for the case that there are two passengers in the vehicle, riding with the characteristic velocity of $30 \mathrm{~m} / \mathrm{s}$ [32] on a good asphalt road, whose time excitation function is shown in Figure 2 [16]. To be more precise, a polyharmonic excitation function is applied because the analyses have shown that it represents a good approximation of real road microprofile, for the applied vehicle velocity of $30 \mathrm{~m} / \mathrm{s}$.

Bearing in mind the observed vehicle vibration model, by use of Newton's law [27,31], the following differential equations of vibration motion of vehicle are obtained:

$$
\begin{aligned}
& m_{1} \ddot{z}_{1}=F_{s}+F_{s h}-F_{t} \\
& m_{2} \ddot{z}_{2}=-F_{s}-F_{s h}
\end{aligned}
$$

where:

- $\ddot{z}_{1}, \ddot{z}_{2}$-accelerations of unsprung and sprung mass measured from the equilibrium position, respectively,

- Fs - force in the spring given by expression (4), 
- $\mathrm{F}_{\text {sh }}$ - force in the shock absorber given by expression (5), and

- $F_{t}$ - radial force in the tire given by expression (6).

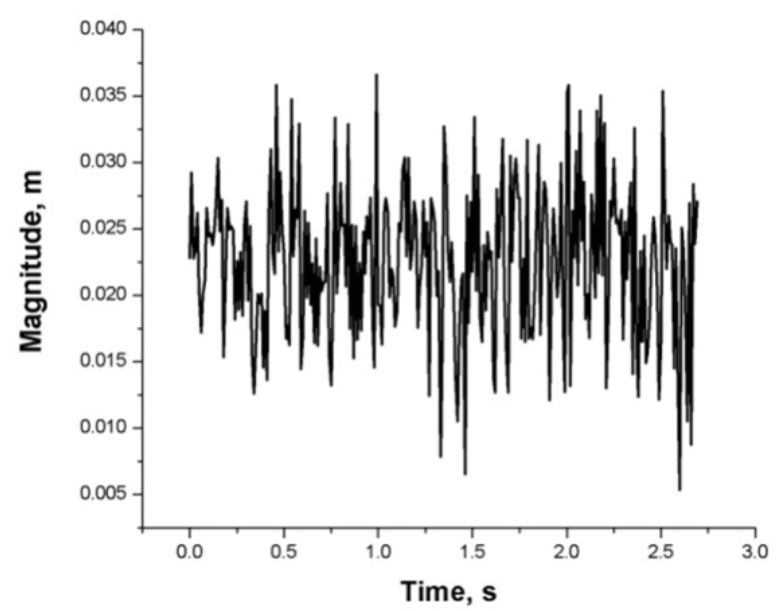

Figure 2: The applied function of road microprofile excitation for the velocity of $30 \mathrm{~m} / \mathrm{s}$

Bearing in mind nonlinear and very complex structure of expressions $(4,5,6)$, even in case of such a simple vehicle model, as well as quasistochastic character of the excitation function, it appears to be obvious that the vehicle model described by equations $(8,9)$ is complex and cannot be solved in finite form.

The analyses have shown that the argument of the tangens hyperbolicus function in the expression (5) - displacement divided with the triple variation - lies in the domain -1.8 to +1.8 (established on the basis of the experimental results $[01,15]$.

It can be noted that the argument of the observed function is usually in the interval -1 to +1 , and the relative error of approximation of the mentioned function with the Maclaurin polynomial of third degree is approx. $9 \%[01,16]$, which is found acceptable.

During the simulation, parameters of the passenger car "Zastava 1100" were utilized, provided by the manufacturer [32], and shown in Table 1.

Table 1: Vehicle parameters

\begin{tabular}{|c|c|c|c|c|}
\hline $\mathrm{C}_{1}, \mathrm{~N} / \mathrm{m}$ & $\mathrm{C}_{2}, \mathrm{~N} / \mathrm{m}^{3}$ & $\mathrm{C}_{3}, \mathrm{~N} / \mathrm{m}$ & $\mathrm{c}_{4}, \mathrm{~N} / \mathrm{m}^{2}$ & $\mathrm{C}_{5}, \mathrm{~N} / \mathrm{m}^{3}$ \\
\hline 50000 & 10000 & 5000 & 500000 & 500000 \\
\hline $\mathrm{x}_{1}, 1 / \mathrm{N}$ & $\mathrm{x}_{2}, / \mathrm{x}_{3}, \mathrm{~s} / \mathrm{s}$ & $\mathrm{x}_{4}, \mathrm{~s}_{2} / \mathrm{m}$ & $\mathrm{x}_{5}, \mathrm{~N} / \mathrm{m}$ & $\mathrm{x}_{6}, \mathrm{~N} / \mathrm{m}$ \\
\hline 20.25 & $0.008 / 0.02$ & -9.51 & -2.091 & 0.0015 \\
\hline
\end{tabular}

It should be pointed out that dimensions of the coefficients in Table 1 are within SI unit system.

\section{METHOD}

Parameters of elasto-damping elements are variable values during the service life. To be more precise, their values tend to descend. For the illustration, Figure 3 shows a typical example of that variation [23], where it is assumed that values of parameters descend linearly with the duration of service, expressed in $\mathrm{km}$. Data from Figure 3 enable analysis of the influence of vibration parameters variation on vehicle dynamic characteristics.

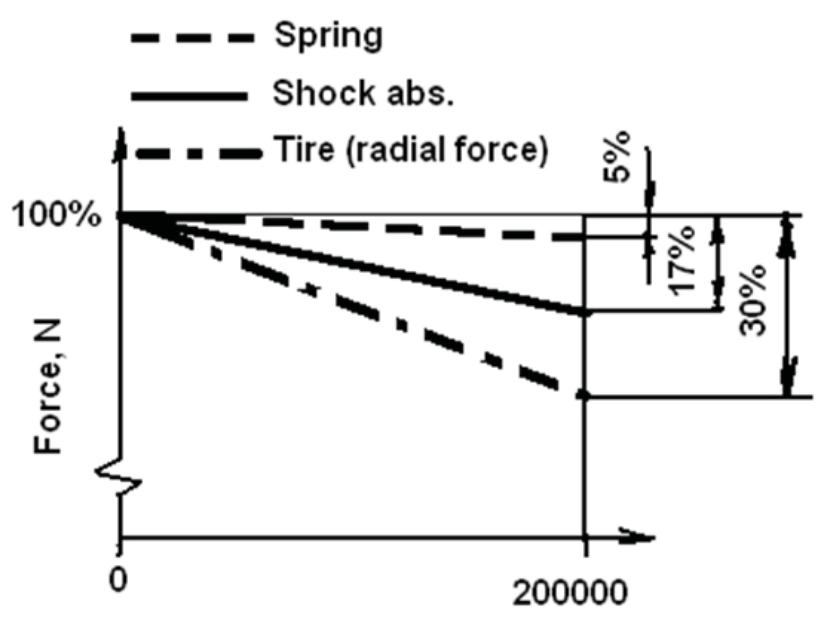

Exploitation, $\mathrm{km}$

Figure 3: Variation of vibration parameters in service

For the analysis of the influence of vehicle dynamic cahracteristics due to variation of parameters of elasto-damping elements in service, two groups of parameters were utilized, taking into account these variations. To be more precise, having in mind Figure 3 , after approximation with streight line, any variation is described by the expression:

$\operatorname{vibpar}(\tau)=\operatorname{vibpar}_{0} \cdot k_{i}$

where:

- $\operatorname{vibpar}(\tau)$ - value of vibration parameter after service of $(\tau)$ kilometers,

- vibpar - value of vibration parameter at the beginning of vehicle service, and

- $k_{i}$ - factor that takes into account degradation of vibration parameters during service.

In order to take into account the influence of aging on vehicle dynamic characteristics, on the basis of the data given in Figure 3, corrective parameters are adopted and given in Table 2 . It should be pointed out that factor $k_{1}$ refers to 
springs, $\mathrm{k}_{2}$ to shock absorbers and $\mathrm{k}_{3}$ to tires, and there were two groups of factors observed: at the beginning of service (group 1) and after 200000 kilometers of service (group 2).

As it has already been pointed out, differential equations $(7,8)$ are solved numerically, by use of method Runge-Kutta, with the sample of increment $0.01 \mathrm{~s}$, in 1024 points, which enabled reliability of the results within the domain $0.1-50 \mathrm{~Hz}$, what is regarded acceptable for this kind of analysis [02-04, 13-15].

On the basis of [02-04], statistical values of errors were calculated. For the signal of 1024 points with the sample of increment 0.01 , number of averaging 256 , bias errors were obtained 0.003 , stochastic error for a single signal 0.10 , and for two signals 0.118 , for spectra. Such small values of errors indicate that these results enable reliable analyses.

Table 2: Corrective factors

\begin{tabular}{|c|c|c|c|}
\hline & $k_{1}$ & $k_{2}$ & $k_{3}$ \\
\hline Group 1 & 1 & 1 & 1 \\
\hline \hline Group 2 & 0,95 & 0,83 & 0,70 \\
\hline
\end{tabular}

\section{ANALYSIS OF THE RESULTS}

On the basis of the calculated time series of vertical vibration of sprung mass, ordinary coherence functions, cross-correlation functions and transfer functions for the initial state were calculated, and also for the state of vibration parameters after $200000 \mathrm{~km}$ of service, by use of software [17, 18], and presented in Figures 4-7.

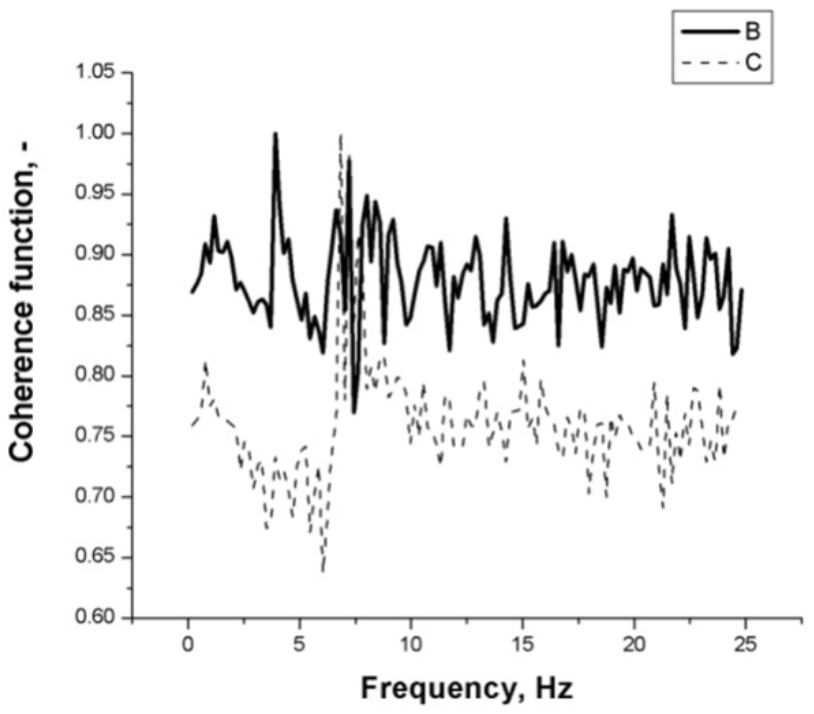

Figure 4: Ordinary coherence function

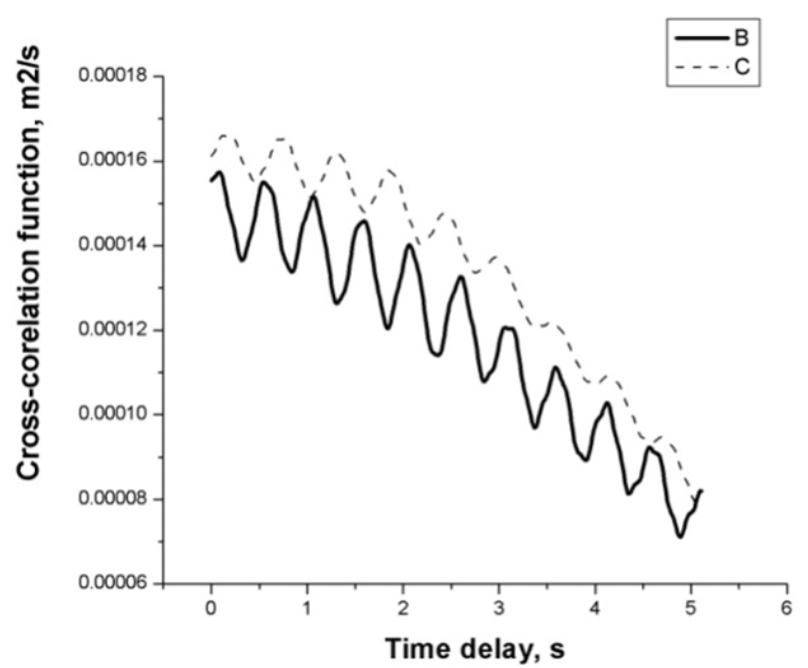

Figure 5: Cross-correlation function

The analysis of the data from the Figure 4 may lead to the conclusion that ordinary coherence function is subject to variation within the interval $0.65-1$, what indicates that the vehicle model is nonlinear [02-04]. Degradation of vibration parameters also influences the value of ordinary coherence function.

Figure 5 presents the variation of cross-correlation function with the increment of time duration. To be more precise, it descends with the time increment and gravitates towards zero value, and also indicates that the process of vibration is stationary, what is understandable when the applied function of excitation is stationary value [02-04]. As in previous case, degradation of vibration parameters influences forced vibration of vehicle sprung mass.

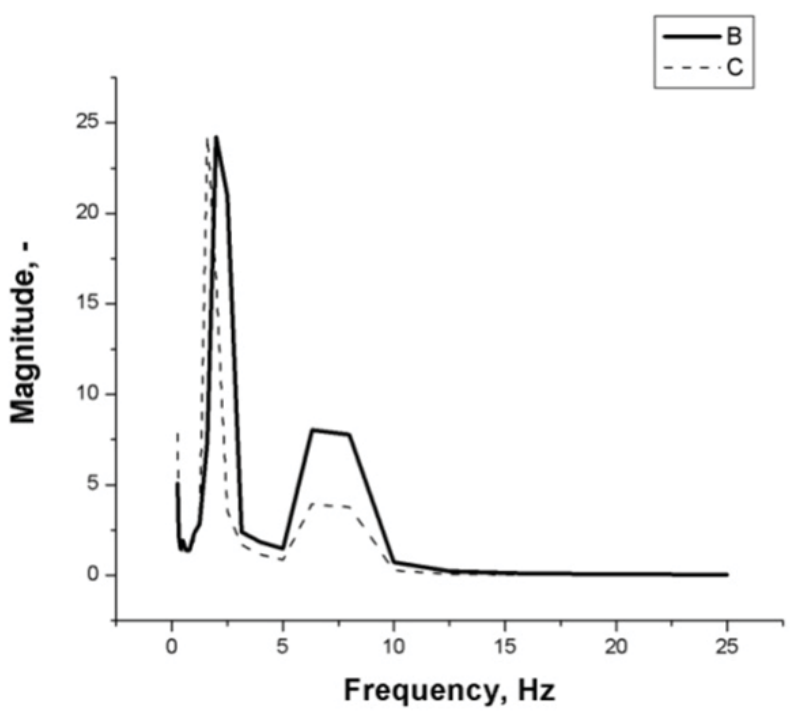

Figure 6: Modulus of transfer function 
The analysis of data from the Figure 6 shows the resonance of sprung mass at approx. 2.5 $\mathrm{Hz}$, and unsprung mass at approx. $7.5 \mathrm{~Hz}$, which confirms the fact that vehicle parameters are well chosen [21]. It is obvious that degradation of vibration parameters leads to a variation of parameters of resonance of sprung and unsprung masses. l.e., since spring and shock absorber cahracteristics descend with the duration of service, it is clear that reduced damping leads to a variation of transfer function amplitude [26]. Variation of vibration parameters also influences the variation of phase angle, Figure 7.

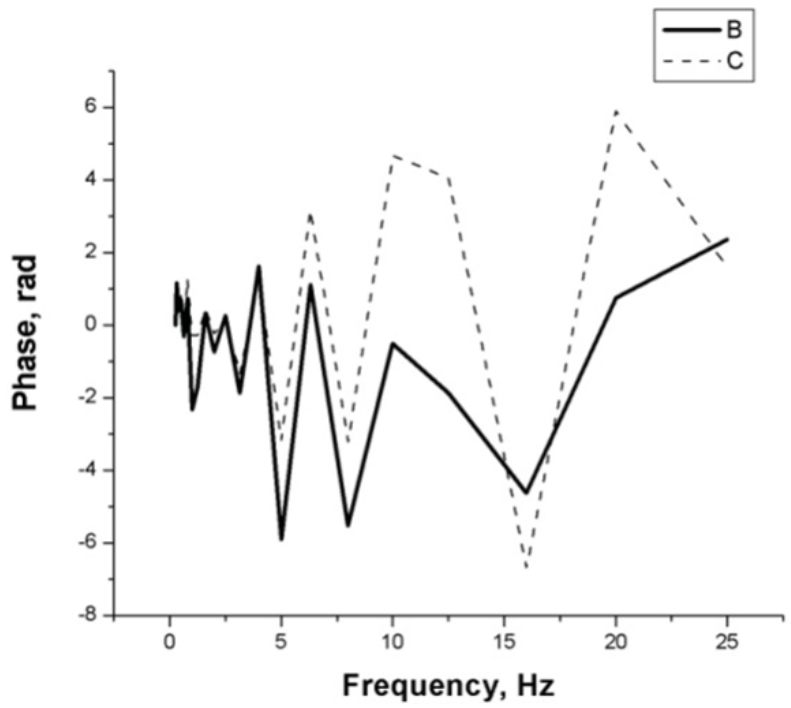

Figure 7: Phase angle of transfer function

It should be noticed that the variation of parameters of resonant point strongly influences parameters of vibration comfort of the vehicle, and degradation of these parameters may lead to a distraction of the vehicle due to unconfortable ride [12-14, 18]. This effect is often noticed in service when shock absorbers are worn, or suspension characteristics degrade to the extent that makes the vehicle unsafe to use. Therefore, it appears to be a need to introduce a degree of the allowed degradation of vibration parameters, what is not the subject of this paper. It is important to point out that the influence of degradation of vibration parameters should be taken into consideration in the process of creating a vehicle model in the early phase of vehicle design.

\section{CONCLUSIONS}

Performed research enabled following conclusions:

- Degradation of vibration parameters during the service influences the variation of characteristics relevant for vehicle vibration comfort.

- The influence of degradation of vibration parameters should be taken into account in vehicle model in the early phase of vehicle design

\section{REFERENCES}

1) Belingardi, G., Demić, M. (2009), A possible model for shock absorber by using the „Black Box" method, Istraživanja i projektovanja za privredu, VII/4, pp. 45-53.

2) Bendat, J. and Piersol, A. (1980), Engineering applications of correlation and spectral analysis, John Wiley and Sons, New York.

3) Bendat, J. and Piersol, A. (2000), Random data analysis and measurement, John Wiley and Sons, London.

4) Bendat, J. (1998), Nonlinear Systems - Techniques and Applications, John Wiley and Sons, London.

5) Demić, M. (2011), Scientific Methods and Technical Development (in Serbian), Mechanical Engineering Faculty, Kragujevac.

6) Demić, M. (1997), The Optimization of Vehicle Vibration Systems (in Serbian), Mechanical Engineering Faculty, Kragujevac.

7) Demić, M. (2004), Design of Passenger Cars (in Serbian), Mechanical Engineering Faculty, Kragujevac.

8) Demić, M. et al. (1984), A Suplement to Standardization of Nonuniformity of Passenger Car Tires with Respect to Oscillatory Comfort and Handling, ISATA, Milan.

9) Demic, M. (1999), The definition of the tires limit of admissible nonuniformity by using the vehicle vibratory model, Vehicle System Dynamics 31 (3), pp. 183-211

10) Demić, M. (1994), Optimization of Vehicles Elasto-Damping Element Characteristics from the Aspect of Ride Comfort, Vehicle System Dynamics, Vol. 23, pp.351-377.

11) Demić, M. (1996), Optimization of Characteristics of Elasto-Damping Elements from the Aspect of Oscillatory Comfort and Vehicle Handling, Int. J. of Vehicle Design, Vol. 17, No 1. 
12) Demić, M., Diligenski, Đ., Demić, I., Demić, M. (2006), A Method of Vehicle Active Suspension Design, Forschung im Ingenieurwessen. 5, 70: DOI 10.1007/s10010-06-0025-, pp 145-158.

13) Demić, M. and Lukić, J. (2008), Human Body Under Two-Directional Random Vibration, Journal of Low Frequency Noise, Vibration and Active Control, 3, pp. 185-201.

14) Demić, M. and Lukić, J. (2009), Investigation of the transmission of fore and aft vibration trough the human body, Applied Ergonomics, XXX, 1-8.

15) Demić, M., Lukić, J. and Milić, Ž. (2002), Some aspects of the investigation of random vibration influence on ride comfort, Journal of Sound and Vibration, 1, pp. $109-129$.

16) Demić, M., Belingardi, G. (2010), A Contribution to shock absorber modelling and Analysis of their Influence on Vehicle ride Characteristics, Journal of Middle European Construction and Design of Cars (MECCA), 01, pp 6-17.

17) Demić, M. (2003), Analsigdem: Software for signal analysis, www.ptt.yu/korisnici/i/m/imizm034/index.swf.

18) Demić, M. (2003), Demparcoh Software, www.ptt.yu/korisnici/i/m/imizm034/index.swf

19) Griffin, M. J. (1990), Handbook of Human Vibration, Academic Press, London.

20) Featherstone, R. (2008), Rigid Body Dynamics, Springer.

21) Genta A. (2003), Motor Vehicle Dynamics. Politecniko di Torino.

22) Gillespie T. (1992), Fundamentals of Vehicle Dynamics. SAE, Warrendale, 1992.
23) Magneti Marelli (2012), Informations.

24) Miliken W.F, Miliken D.L. (1995), Race Car Vehicle Dynamics. SAE, Warrendale.

25) Miloradović, D. (2012), Research of Mechanical and Functional Couplings of Vehicle Dynamic System from the Aspect of Required Performances (in Serbian), PhD Thesis. Faculty of Engineering Sciences, Kragujevac.

26) Rajamani, R. (2005), Vehicle Dynamics and Control, University of Minesota.

27) Rašković, D. (1974), Analytical Mechanics- A Brief Course (in Serbian). Mechanical Engineering Faculty, Kragujevac.

28) Sekulić, D., Dedović, V. (2008), Simulation of oscillatory behavior of buses with conventional and active suspension systems. Journal of Applied Engineering Science, Vol. 6, No. 20, pp. 23-32

29) Sekulić, D., Dedović, V.(2011), Effects of vibration on user comfort intercity buses using oscillatory model with seven degrees of freedom using ADAMS / View software. Journal of Applied Engineering Science, Vol. 9, No. 3, pp. 401-410

30) Simić, S., S. (2006), Analytical Mechanics: Dynamics, Stability, Bifurcations (in Serbian). FTN Editions, Novi Sad.

31) Fabien, B. (2009), Analitical System Dynamics - Modeling and Simulation, Springer.

32) Zastava Informations (in Serbian) (19772010) Kragujevac.

Paper sent to revision: 24.09.2012.

Paper ready for publication: 03.12.2012. 